Case report

\title{
A different management of saphenous vein graft failure related to cardiac tamponade following coronary surgery
}

\author{
Hamit Serdar Başbuğ ${ }^{\mathrm{a}, *}$, Ahmet Karakurt ${ }^{\mathrm{b}}$, Hakan Göçer ${ }^{\mathrm{a}}$, Yalçın Günerhan ${ }^{\mathrm{a}}$, Kanat Özışık ${ }^{\mathrm{a}}$ \\ a Department of Cardiovascular Surgery, Kafkas University Faculty of Medicine, Kars, Turkey \\ b Department of Cardiology, Kafkas University Faculty of Medicine, Kars, Turkey
}

\section{A R T I C L E I N F O}

\section{Article history:}

Received 13 December 2015

Received in revised form 22 January 2016

Accepted 26 January 2016

Available online 3 March 2016

\section{Keywords:}

Cardiac tamponade

Coronary surgery

Saphenous vein graft

\begin{abstract}
A B S T R A C T
Cardiac tamponade is a state of constriction of the heart with an excessive fluid or hematoma resulted from various conditions. Postoperative tamponade can occur after coronary bypass surgery. Despite it is uncommon, its results may have a high risk of mortality and morbidity. Acute postoperative cardiac tamponade reveals a vast spectrum of symptoms. Moreover, a compression over the saphenous vein graft is the worst complication that should be managed without delay. We report a rare case of saphenous vein graft failure due to the cardiac tamponade following a coronary surgery and its management with a practical measure.

(c) 2016 The Society of Cardiovascular Academy. Production and hosting by Elsevier B.V. All rights reserved. This is an open access article under the CC BY-NC-ND license (http://creativecommons.org/licenses/by-nc-nd/4.0/).
\end{abstract}

\section{Introduction}

Acute postoperative cardiac tamponade is an uncommon but potentially fatal complication occurred within the seven days after cardiac surgery. ${ }^{1}$ The incidence of this entity ranged from $0.1 \%$ to $6 \%$ and associated with preoperative or postoperative anticoagulation ${ }^{2}$. Cardiac tamponade often presents with the reduction in blood pressure (BP), tachycardia, increased central venous pressure, decreased urine output and respiratory distress ${ }^{3}$. Thus, prompt diagnosis and effective management are needed to prevent unwanted complications like circulatory and cardiorespiratory collapse. ${ }^{4}$ However, the recent literature does not reveal enough publications related to the complications and managements of cardiac tamponade following open heart surgery. In this article, we report the management of a saphenous vein graft compression and failure due to the cardiac tamponade. Saphenous vein failure due to the external compression is a rare and lifethreatening complication of cardiac tamponade encountered after coronary surgery.

\section{Case report}

A 62-year-old male was performed an urgent coronary bypass graft (CABG) operation due to acute myocardial infarction (AMI). Right coronary artery (RCA) and the circumflex artery (CxA) were revascularized with saphenous vein grafts and the left anterior descendent (LAD) artery was bypassed with internal mammary artery (IMA).

\footnotetext{
* Corresponding author. Tel.: + 90505 2612372; fax: +90 4742251193.

E-mail address: s_basbug@hotmail.com (H.S. Başbuğ).

Peer review under responsibility of The Society of Cardiovascular Academy.
}

The operation was accomplished with no intraoperative complication. Intensive care unit parameters were normal including chest roentgenogram (Fig. 1A). However, there was a continuous bleeding through the drain tubes. Abundant bleeding $(200 \mathrm{ml} / \mathrm{h})$ was related to the preoperative administration of $600 \mathrm{mg}$ of Clopidogrel, which is a routine protocol that has been applied to all AMI patients. Transfusion of thrombocyte, fresh frozen plasma and blood products could not restore the hemoglobin levels. After $10 \mathrm{~h}$ of medical treatment, total bleeding reached to $2000 \mathrm{ml}$. Posteroanterior chest roentgenogram showed a widened mediastinum (Fig. 1B). Echocardiography revealed a massive global pericardial effusion that was $30 \mathrm{~mm}$ on the apex and $34 \mathrm{~mm}$ on the posterior segment in long axis examination. In apical fourchamber view, diastolic dysfunction of the right atrium was observed that was consistent with cardiac tamponade. The ejection fraction (EF) was measured as $52 \%$ with the Simpsons method (Preoperative EF was $54 \%$ ). There was a mild hypokinesia in the posterobasal $2 / 3$ of the myocardium which had also existed before the operation. Additionally, electrocardiography showed moderate depressions in D3 and AVF leads that implicated a graft failure. BP was progressively dropped to $75 / 35 \mathrm{mmHg}$ that made us consider chest re-exploration with the diagnosis of cardiac tamponade. Coronary angiography was not performed before the reoperation in this case. Circulatory collapse necessitated an immediate reoperation without preceding angiography. The patient was reopened, and the hematoma was evacuated. No imminent surgical bleeding foci were found. However, the saphenous vein graft of the RCA was pulseless and found to be squeezed and thrombosed during both systole and the diastole due to the compression of massive hematoma. The graft of CxA was normal. The RCA graft failure was thought to be caused by the cardiac tamponade as the ECG of the patient had been otherwise normal until the cardiac 

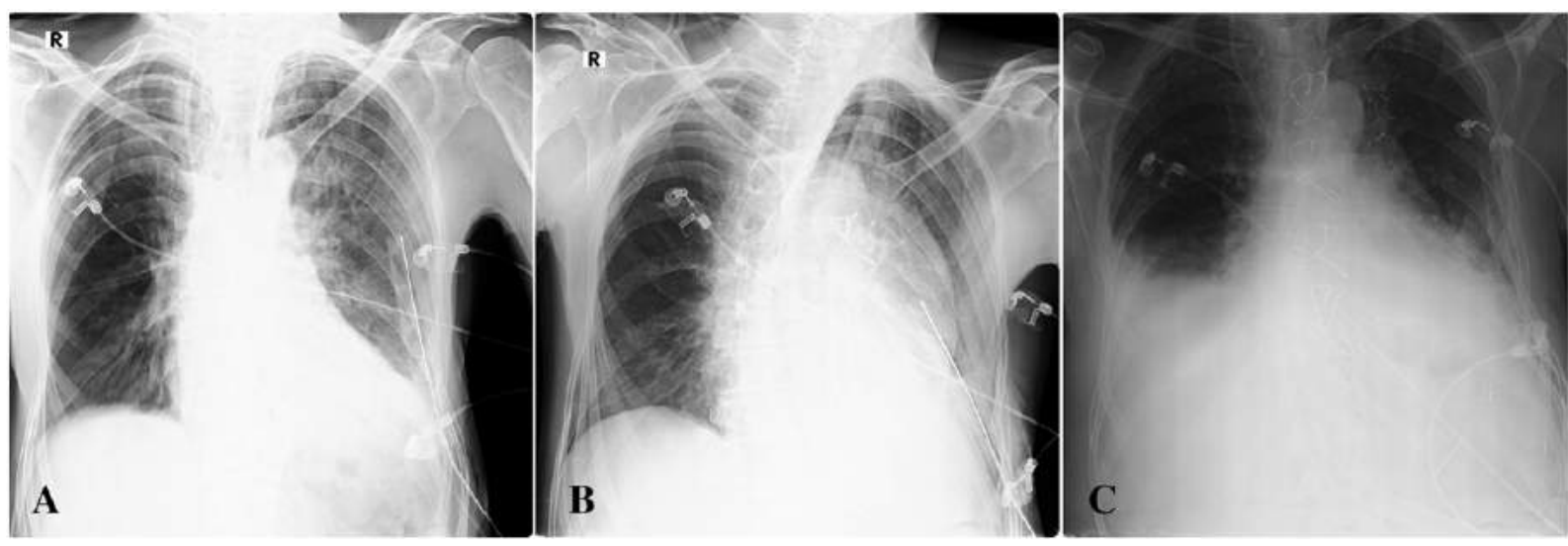

Fig. 1. Chest roentgenogram (A) Early postoperative (B) Cardiac tamponade (C) After reopening.

tamponade clinic was started. Although a thrombectomy was initially performed to the RCA graft using Fogarty catheter, circulation and pulsation could not be restored. Failed graft was decided to be replaced. A new saphenous vein graft was harvested and interposed between the proximal portion of the CXA graft and the distal part of the failed RCA graft (Fig. 2). ECG revealed a dramatic improvement in inferior leads and the BP was increased. The patient was extubated on the sixth hour postoperatively and discharged on the seventh day after surgery with a normal chest roentgenogram (Fig. 1C).

\section{Discussion}

Surgical re-exploration due to bleeding after cardiac operations accompanies with various complication affecting the postoperative course and leads to increased mortality and morbidity. ${ }^{5}$ However, postponing the timing of reoperation despite the symptoms of cardiac tamponade also presents a risk when the delay creates a hemodynamic instability and increases the need for the excessive amount of allogeneic blood products. ${ }^{6}$

Cardiac tamponade is the collection of fluid in the pericardial cavity and compression of the heart causing hemodynamic instability due to the compromised contractility. ${ }^{7}$ In all types of cardiac tamponade, including the tamponade after cardiac surgery, the mediastinum stretches to accommodate the increased volume. When the expansion capacity of the mediastinum is no longer available, intrapericardial pressure starts to rise. If this pressure exceeds the intracardiac pressure, the contractile capability of the heart diminishes. ${ }^{4}$ This increased pressure may also cause a compression over the vein grafts as in this case. The consequences may vary from the transient collapse of the vein graft to total obstruction as a result of graft thrombosis. In the event of a graft failure after the cardiac tamponade, aortocoronary bypass should inevitably be renewed. However, conducting this reoperation under the extracorporeal circulation may cause further impairment of the myocardium. Thus, instead of the constitution of a re-arrest, the off-pump CABG choice should be taken into consideration if possible. As we present in this report, a new graft may easily be implanted between the other intact graft and the failed graft. This preference not only protects the patient from an extensive reoperation but also enables the surgeon to perform the revascularization easily, fastly and practically with a reduced risk of mortality.

Early graft failure (within the first 30 days after surgery) is seen in approximately 5 to $10 \%$ of saphenous vein grafts. These occlusions may be due to thrombosis that is related to technical problems at the anastomosis or the injury due to the manipulation during harvesting. ${ }^{8}$

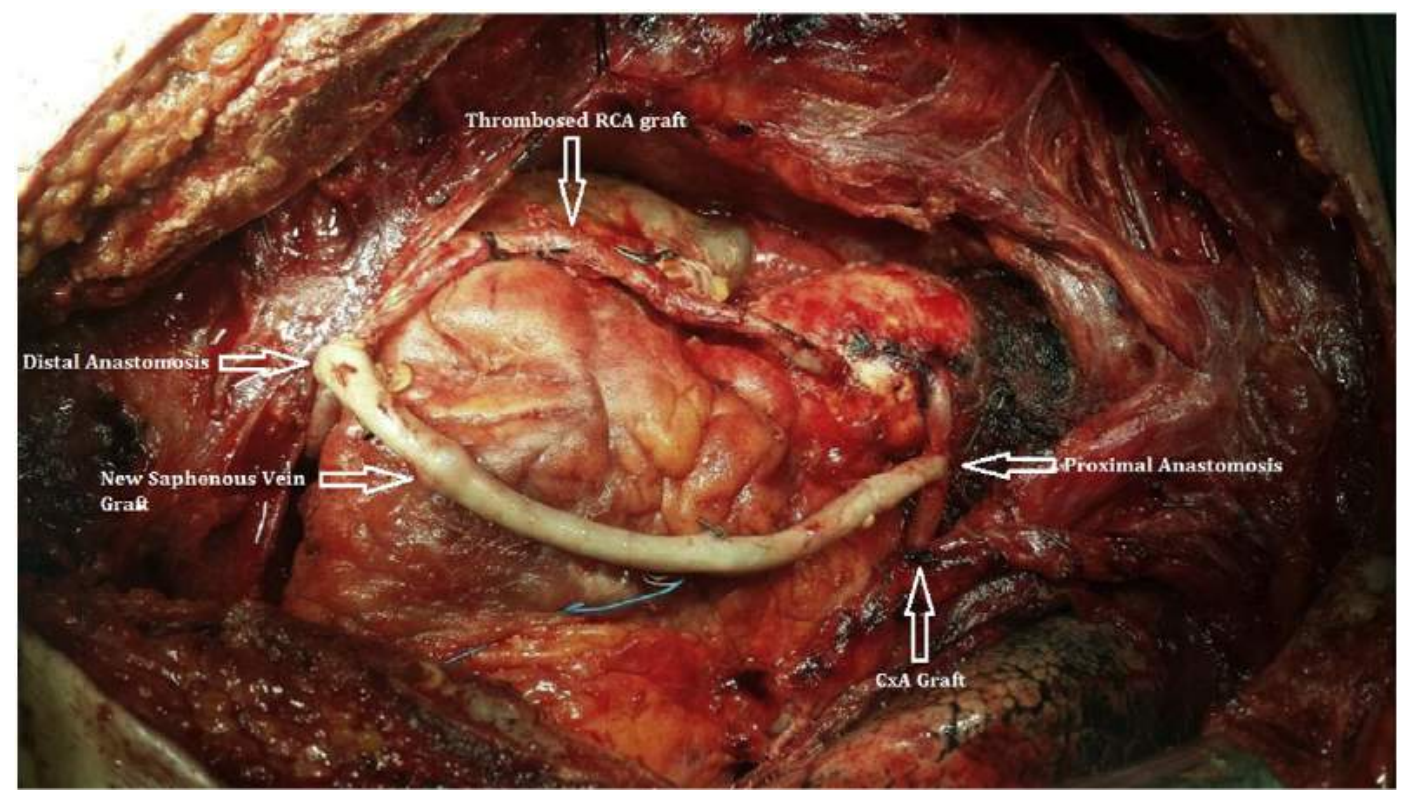

Fig. 2. A new saphenous vein graft was interposed between the two previous saphenous vein grafts. 
The risk of early graft occlusion appears to be reduced by starting Acetylsalicylic acid therapy, which is typically started within six hours following surgery.

As a conclusion, this case implicates the risk of compression and failure of the saphenous vein grafts in cardiac tamponade following CABG. The management should be considered in a more practical way as in this case.

\section{Conflict of interest}

None declared.

\section{References}

1. Ranucci M, Bozzetti G, Ditta A, Cotza M, Carboni G, Ballotta A. Surgical reexploration after cardiac operations: why a worse outcome? Ann Thorac Surg. 2008;86(5):1557-1562.
2. Biancari F, Mikkola R, Heikkinen J, Lahtinen J, Airaksinen KJ, Juvonen T. Estimating the risk of complications related to re-exploration for bleeding after adult cardiac surgery: a systematic review and meta-analysis. Eur J Cardiothorac Surg. 2012;41(1): $50-55$

3. Grumann A, Baretto L, Dugard A, et al. Localized cardiac tamponade after open-heart surgery. Ann Thorac Cardiovasc Surg. 2012;18(6):524-529.

4. Carmona P, Mateo E, Casanovas I, et al. Management of cardiac tamponade after cardiac surgery. J Cardiothorac Vasc Anesth. 2012;26(2):302-311.

5. Ranucci M, Bozzetti G, Ditta A, Cotza M, Carboni G, Ballotta A. Surgical reexploration after cardiac operations: why a worse outcome? Ann Thorac Surg. 2008;86(5): 1557-1562.

6. Choong CK, Gerrard C, Goldsmith KA, Dunningham H, Vuylsteke A. Delayed re-exploration for bleeding after coronary artery bypass surgery results in adverse outcomes. Eur J Cardiothorac Surg. 2007;31(5):834-838.

7. Roy CL, Minor MA, Brookhart MA, Choudhry NK. Does this patient with a pericardial effusion have cardiac tamponade? JAMA 2007;297(16):1810-1818.

8. Dauerman HL, Cutlip DE, Sellke FW. Intracoronary thrombolysis in the treatment of graft closure immediately after CABG. Ann Thorac Surg. 1996;62(1):280-283. 